\title{
Radiation Component Characteristic under Consideration of Biberman Factor in Wavelength emitted from High Temperature Argon
}

\author{
Satoshi Honda Student Member (Chuo University) \\ Toru Iwao Member (Musashi Institute of Technology) \\ Motoshige Yumoto Member (Musashi Institute of Technology) \\ Tsuginori Inaba Senior Member (Chuo University)
}

Keywords: radiant power density, continuum radiation, line emission, Argon, wavelength, high temperature, plasma arc, Biberman factor

When a reduction of the waste and dissolution of the iron are carried out by using a high temperature medium, the radiant power emitted from the medium should be suppressed. On the contrary, it is useful for lighting and treatment of hazardous wastes because it has a highly intense radiant energy. In this paper, we tried to calculate the number density and radiant power density under consideration of atmospheric high temperature pure argon (Ar) which is frequently used for a plasma arc to know the basic theory of radiant power density for the development of the plasma treatment by using radiant power. The number density and radiant power density of $\mathrm{Ar}$ I-Ar III are calculated ${ }^{(1)-(3)}$ with each rays and wavelength at 1,000$30,000 \mathrm{~K}$ and $200-1,000 \mathrm{~nm}$ in wavelength as shown in Fig. 1. The total radiation power density increases with increasing the temperature up to $15,000 \mathrm{~K}$ and keeps almost constant over it. The continuum spectrum of Ar I increases up to $14,000 \mathrm{~K}$ with increasing the temperature. However, it decreases over 14,000 K. The continuum spectrum of Ar II is ten times as high as the line spectrum of $\mathrm{Ar}$ I over $14,000 \mathrm{~K}$. The line and continuum spectrum of Ar III increases with increasing the temperature, and the value is level off at $26,000 \mathrm{~K}$. The recombination radiation of Ar II-ufb and Ar III-ufb is higher than the bremsstrahlung Ar II-uff and Ar III-uff at 15,000 K. The bremsstrahlung emitted from Ar I-uff is dominant in the continuum spectrum of Ar I. The u-Ar II is higher than u-Ar I in UV rays. However, the u-Ar I goes over u-Ar II in IR rays. The Ar II-ufb is higher than other continuum spectrum. Therefore, the recombination radiation becomes more dominant with wavelength. The UV rays is to be $50 \%$, and the UV and VR: visible rays are dominant. Most UV and VR rays are emitted from Ar II-ufb. Therefore, the radiation emitted from the UV rays of argon is dominant due to recombination radiation. Therefore, the radiation emitted from argon could apply to waste treatment because of highly intense UV rays.

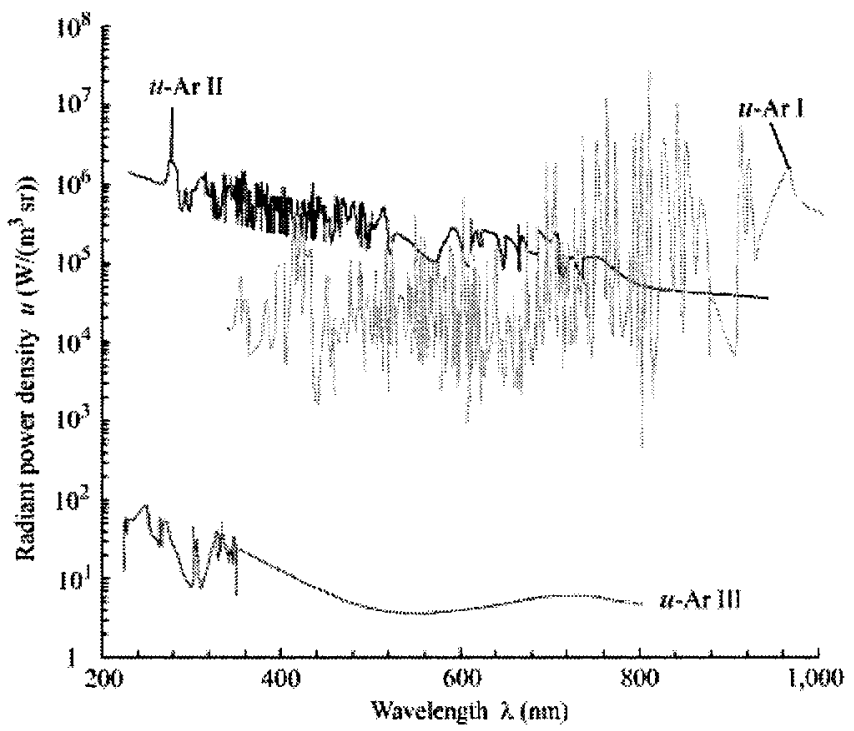

Fig. 1. Radiant power density emitted from Ar in wavelength at $15,000 \mathrm{~K}$ and $0.1 \mathrm{MPa}$

\section{References}

( 1 ) H.P. Schmidt and G. Speckhofer: IEEE Trans. Plasma Sci., Vol.24, No.4, pp.1229-1238 (1996-8)

( 2 ) E.J. Robinson and S. Geltman: Phys. Rev., Vol.153, pp.4-8 (1967)

( 3 ) G.J. Bastiaans and R.A. Mangold: Spectrochim Acta, Vol.40B, No.7, pp.885892 (1985) 


\title{
Biberman Factorを考慮した高温アルゴンガスにおける 波長別放射成分特性
}

\author{
学生員 本田 賢* 正 員 岩尾 徹** \\ 正 員 湯本 雅恵** 上級会員 稲葉 次紀*

\begin{abstract}
Radiation Component Characteristic under Consideration of Biberman Factor in Wavelength emitted from High Temperature Argon
\end{abstract}

\begin{abstract}
Satoshi Honda*, Student Member, Toru Iwao**, Member, Motoshige Yumoto**, Member,
\end{abstract} \\ Tsuginori Inaba*, Senior Member
}

\begin{abstract}
When a reduction of the waste and dissolution of the iron are carried out by using a high temperature medium, the radiant power emitted from the medium should be suppressed. On the contrary, it is useful for lighting and treatment of hazardous wastes because it has a highly intense radiant energy. In this paper, we tried to calculate the number density and radiant power density under consideration of atmospheric high temperature pure argon (Ar) which is frequently used for a plasma arc to know the basic theory of radiant power density for the development of the plasma treatment by using radiant power. Considering kinds of particles: Ar I Ar IV and e, temperature domain: 1,000 K 30,000 K and wavelength domain: $200 \mathrm{~nm} \sim 1,000 \mathrm{~nm}$, and Biberman factor: changeable in wavelength, we calculated the line and continuum radiant power density as ingredients of the radiant power, and mentioned the above characteristics in every temperature, particle and wavelength range. As a result, a dominant wavelength area became ultraviolet to visibile by making Biberman factor change.
\end{abstract}

キーワード：放射パワー密度, 連続スペクトル, 線スペクトル, アルゴン, 波長, 超高温, プラズマアーク, Biberman factor Keywords: radiant power density, continuum radiation, line emission, Argon, wavelength, high temperature, plasma arc, Biberman factor

\section{1. はじめに}

焼却飛灰の減容や溶融鉄の精密保温を行う時には，超高 温性を持つアーク放電が用いられているが，アーク放電が 発生した場合，その超高温性により必ず放射パワーが発生 する (1) (5)。この放射パワーは，その高輝度性を利用した大 規模照明への応用や，燃焼を伴わないクリーンな加熱源と して有害廃棄物処理や表面処理・改質などに利用すること が検討されており ${ }^{(6)(8)}$, 放射パワーを活用することは, アー ク放電を工業的に利用する上で，大変に重要なことである。 具体的には，新金属高融点材料の生成，紫外線を利用した 有害廃棄物の処理 ${ }^{(9)}$, 超高温性と赤外光による高輝度性を

\footnotetext{
* 中央大学大学院理工学研究科

干112-8551 東京都文京区春日 1-13-27

Graduate School of S\&E, Chuo University

1-13-27, Kasuga, Bunkyo-ku, Tokyo 112-8551

** 武蔵工業大学工学部

T 158-8557 東京都世田谷区玉堤 1-28-1

Faculty of Engineering, Musashi Institute of Technology

1-28-1, Tamazutsumi, Setagaya-ku, Tokyo 158-8557
}

融合した高効率の溶融及び廃棄物処理装置 (7) の開発, 可視 領域を用いて災害現場, 海中農園, 景観照明などで利用さ れる大規模照明などが考えられる。このようなアーク放電 は, 高温気体の一つであり, その高温気体の放射に関する基 礎特性を把握することは, アーク放電の解明に重要である。 過去の研究において, 温度変化の高温アルゴンガスにおける 放射パワー密度は詳細に計算されている ${ }^{(10) \sim(14)}$ が, 波長別の 放射パワー密度に関する計算が行われた例は少ない。特に, 従来あまり考慮されていない紫外領域での放射パワー密度 に影響を及ぼす Biberman facftor ${ }^{(15)(16)}$ の波長依存性を考慮 した放射パワー密度の検討を行った例はほとんど無い。本 論文では,アルゴンガスの放射パワー密度特性を求めるため に粒子組成を計算し, 主要因である Biberman factor を一定 (=1.5) ではなく波長により変化 ${ }^{(15)}$ させ, 線スペクトル・連 続スペクトル・放射パワー密度を圧力 $0.1 \mathrm{MPa}$ 下で温度領 域 $T=1,000 \sim 30,000 \mathrm{~K}$, 波長領域 $\lambda=200 \sim 1,000 \mathrm{~nm}$ として算出した。特にBiberman factorの波長による変化の 具体的な放射パワー密度成分の内訳を示すため, 制動放射 と再結合放射から成る連続スペクトルの各成分を波長・温 
度毎に計算し，各種放射，波長毎にまとめた。放射パワー密 度の内訳を示すことで，その高温ガスの支配的な粒子や波 長領域が分かり，応用を考えたときに役立つデー夕となる。

\section{2. 高温アルゴンガスの粒子組成}

放射パワーを求めるため，高温アルゴンガスの粒子組成 計算を行った。考慮した粒子は, ArI, ArII, ArIII, ArIV, 電子 e $の ~ 5$ 種類, 対象温度領域は, $1,000 \sim 30,000 \mathrm{~K}$ とし た。各粒子の解離・電離電圧（エネルギー）を表 1 に示す。 なお，添字 $Z$ は電離状態 $(Z=\mathrm{I}$ ：基底）を示す。

$\langle\mathbf{2} \cdot \mathbf{1}\rangle$ 連立方程式 計算方法は, デバイ遮蔽を考慮 ${ }^{(17)}$ したSahaの電離式, 気体の状態方程式, 電荷中性保存式を 連立させ，Newton-Raphson 法を用いて計算した ${ }^{(18)}$ 。

$\langle\mathbf{2} \cdot \mathbf{2}\rangle$ 粒子組成計算結果 図 1 に, 高温 $\mathrm{Ar}$ ガスの 粒子組成 $n$ を示す。温度 $5,000 \mathrm{~K}$ 以下では ArI が支配的と なり，温度領域 $5,000 \mathrm{~K}$ から 17,000 K 付近では, ArI が電 離し ArII になり，電子密度が上昇した。18,000 K 付近か ら ArII の粒子密度は，ArII の電離により ArIII が増加し始 めることにより減少する。粒子密度の総和は, 気体の状態 方程式で圧力一定により, 温度増加と共に減少する。温度 が $15,000 \mathrm{~K}$ 付近では，ArI と ArII，e の粒子密度の大きさ は逆転する。全体に対する個数割合は, ArI：26\%, Ar II： $37 \%$, Ar III：0\%，ArIV：0\%，e：37\%と算出された。温度 が 20,000 K 付近では ArI と ArIIIの粒子密度の大きさは逆 転する。全体に対する個数割合は，ArI：1\%，Ar II：48\%，

表 1 電離電圧 (エネルギー)

Table 1. Ionized voltages (energy).

\begin{tabular}{|c|c|c|c|c|c|}
\hline \multicolumn{4}{|c|}{ Status } & \multicolumn{2}{|c|}{ Voltage(energy) } \\
\hline $\operatorname{ArI}$ & $\Longleftrightarrow$ & $\mathrm{Ar}$ II & $\left(\mathrm{Ar}^{+}\right)$ & $15.759 \mathrm{eV}$ & $\left(2.52 \times 10^{-18} \mathrm{~J}\right)$ \\
\hline $\operatorname{Ar}$ II & $\Longleftrightarrow$ & Ar III & $\left(\mathrm{Ar}^{2+}\right)$ & $27.629 \mathrm{eV}$ & $\left(4.42 \times 10^{-18} \mathrm{~J}\right)$ \\
\hline Ar III & $\Longleftrightarrow$ & ArIV & $\left(\mathrm{Ar}^{3+}\right)$ & $40.74 \mathrm{eV}$ & $\left(6.52 \times 10^{-18} \mathrm{~J}\right)$ \\
\hline
\end{tabular}

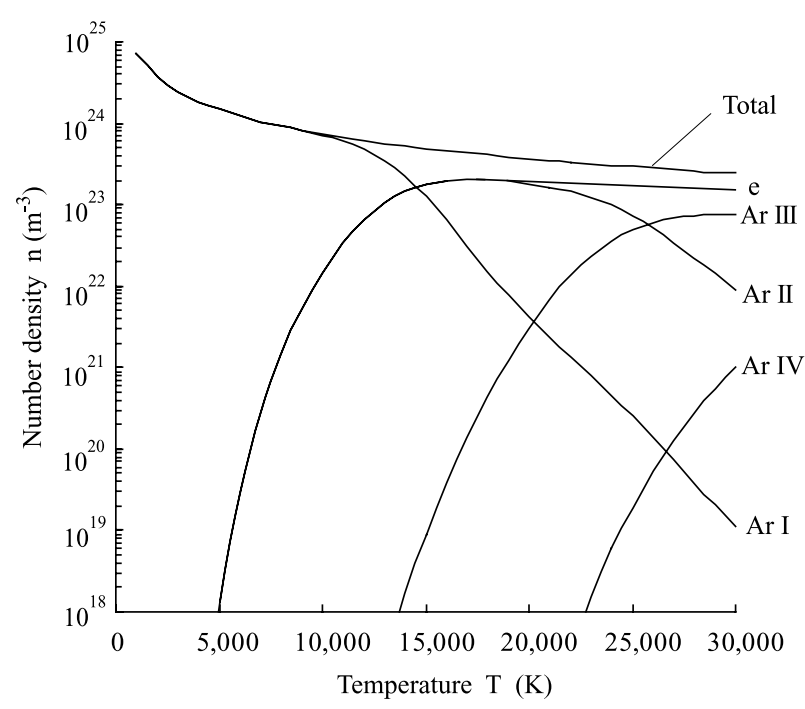

図 1 高温 Ar ガスの粒子組成 (0.1 MPa)

Fig. 1. Number density of $\mathrm{Ar}$ in high temperature at $0.1 \mathrm{MPa}$.
ArIII: $1 \%, \operatorname{ArIV}: 0 \%, \mathrm{e}: 50 \%$ と算出された。温度 $26,000 \mathrm{~K}$ 付近では ArII と Ar III の粒子密度の大きさが逆転した。全 体に対する個数割合は, ArI：0\%, Ar II : 18\%, Ar III：21\%, $\operatorname{ArIV}: 0 \%$, e：61\%と算出された。全体から見ると, ArIV の割合はまだ小さい。30,000 K になると ArIII, ArII, ArIV の順に一桁ずつ低下するが，ArIV はまだ上昇し存在感が生 じる。

\section{3. 放射パワー密度}

〈3・1〉計算方法 高温 $\mathrm{Ar}$ ガスの粒子組成計算結果と $\mathrm{NIST}^{(19)}$ の原子ラインデータベースを用いて，原子やイオ ンによる線スペクトル ${ }^{(20)}$, 及び, 制動放射と再結合放射に よる連続スペクトルの寄与を考慮した下式 ${ }^{(10)} よ り ，$ 放射パ ワー密度 $u\left(\mathrm{~W} /\left(\mathrm{m}^{3} \cdot \mathrm{sr}\right)\right)$ を算出した ${ }^{(15)(21)(22) 。 こ こ て ゙, ~} u_{\text {cont }}$ は連続スペクトルからの放射パワー密度を， $u_{\text {line }}$ は線スペ クトルからの放射パワー密度を示す。

$$
u=u_{\text {cont }}+\sum u_{\text {line }}
$$

〈3・1・1〉 線スペクトル＼cjkstart原子あるいはイオンのエネ ルギー準位は核外電子の配置によって決まる。熱平衡状態 にある高温気体を構成する粒子がエネルギー状態上準位か ら下準位に遷移するときに放射される線スペクトルは次式 によって表される。

$$
u_{\text {line }}=\frac{n_{i \mathrm{Z}}}{4 \pi Q_{i \mathrm{Z}}} \frac{h c}{\lambda_{m}} g_{m i \mathrm{Z}} A_{m n i \mathrm{Z}} \exp \left(-\frac{E_{m i \mathrm{Z}}}{k T}\right) \ldots \ldots \ldots
$$

ここで, 分配関数 $Q$, プランク定数: $h=6.626 \times 10^{-34} \mathrm{~J} \cdot \mathrm{s}$, 光速 : $c=2.998 \times 10^{8} \mathrm{~m} / \mathrm{s}$ ，ボルツマン定数 $: k=1.381 \times$ $10^{-23} \mathrm{~J} / \mathrm{K}$, 縮退度 $: g$, 上準位 $m$ から下準位 $n$ へ遷移すると きの遷移確率: $A_{m n}\left(\mathrm{~s}^{-1}\right)$, 波長 : $\lambda_{m}(\mathrm{~m})$, 上準位エネルギー： $E_{m}(\mathrm{~J})$ である。

$\langle\mathbf{3 \cdot 1 \cdot 2 \rangle}$ 連続スペクトル＼cjkstart高圧・高温ガスからの連続 スペクトルとしては，制動放射および再結合放射が支配的 である。

$$
u_{c o n t}=u_{f b}+u_{f f}^{e i}+u_{f f}^{e a}
$$

自由電子が中性原子の重力場やイオンのクーロン電場で 減速されるときに放出されるのが制動放射 $\left(u_{f f}\right)$ (free-free emission) である。 $u_{f f}^{e i}$ は電子 $e$ とイオン $i$ にる制動放射, $u_{f f}^{e a}$ は電子と中性原子 $a$ による制動放射を示す。

$$
\begin{aligned}
u_{f f}^{e i}= & \sum_{i} C_{1} \frac{n_{e} n_{i}}{\lambda^{2} \sqrt{T_{e}}} Z_{e f f, i}{ }^{2} \\
& \times \exp \left(-\frac{h c}{\lambda k T_{e}}\right) \xi_{f f}\left(\lambda, T_{e}, i\right) \Delta \lambda \ldots \ldots \ldots \\
u_{f f}^{e a}= & C_{2} \frac{n_{e} n_{a}}{\lambda^{2}} \sqrt{T_{e}^{3}} S\left(T_{e}\right)\left[\left(1+\frac{h c}{\lambda k T_{e}}\right)^{2}+1\right] \\
& \times \exp \left(-\frac{h c}{\lambda k T_{e}}\right) \Delta \lambda \ldots \ldots \ldots \ldots \ldots
\end{aligned}
$$

イオンと自由電子が再結合する際に放出される連続スぺ 
クトルが再結合放射 $\left(u_{f b}\right)$ (free-bound emission) である。

$$
\begin{aligned}
u_{f b}= & \sum_{i} C_{1} \frac{n_{e} n_{i}}{\lambda^{2} \sqrt{T_{e}}} Z_{e f f, i}{ }^{2}\left[1-\exp \left(-\frac{h c}{\lambda k T_{e}}\right)\right] \\
& \times \frac{g_{1, i}}{Q_{i}} \xi_{f b}\left(\lambda, T_{e}, i\right) \Delta \lambda \ldots \ldots \ldots \ldots \ldots
\end{aligned}
$$

また，それぞれに用いた定数 $C_{1}, C_{2}$ は，次式で示される。

$$
\begin{aligned}
C_{1} & =\frac{1}{\left(4 \pi \epsilon_{0}\right)^{3}} \frac{16 \pi e^{6}}{3 c^{2}\left(6 \pi m_{e}^{3} k\right)^{\frac{1}{2}}} \\
& =1.63 \times 10^{-43} \mathrm{~W} \cdot \mathrm{m}^{4} \cdot \mathrm{k}^{\frac{1}{2}} / \mathrm{sr} \cdots \\
C_{2} & =\frac{1}{\left(4 \pi \epsilon_{0}\right)} \frac{32 e^{6}}{3 c^{2}}\left(\frac{k}{2 \pi m_{e}}\right)^{\frac{3}{2}} \\
& =1.026 \times 10^{-34} \mathrm{~W} \cdot \mathrm{m}^{2} /\left(\mathrm{k}^{\frac{3}{2}} \cdot \mathrm{sr}\right)
\end{aligned}
$$

ただし, 素電荷量 $: e=1.602 \times 10^{-19} \mathrm{C}$, 真空の誘電率 $: \epsilon_{0}=$ $8.854 \times 10^{-12} \mathrm{~F} / \mathrm{m}$, 電子の質量 : $m_{e}=9.911 \times 10^{-31} \mathrm{~kg}$, 有効 電荷数: $Z_{e f f, i}$, 中性粒子一電子間衝突断面積: $S\left(T_{e}\right)\left(\mathrm{m}^{2}\right)^{(23)}$, Biberman factor: $\xi_{f f}=\xi_{f b}$ である。この Biberman factor は吸収を考慮しない放射パワー密度（(4)，(6) 式）に 顕著に影響するので，今回，吸収を考慮した放射パワー密 度 (10) (14)(24) (26) の計算は行っていない。

〈3.2〉 温度別全放射パワー密度 $\boldsymbol{u}_{\text {total }}$ 文献 (17), (19) の值を用いて波長に関して Biberman factor を変化させた後 の全放射パワー密度を図 2 に示す。図中において，線スペ クトルと連続スペクトルをそれぞれ ArI, ArII, ArIII, ArIV に分けて示した。実線の全放射パワー密度 $u_{\text {total }}$ は，ピー クを迎える $15,000 \mathrm{~K}$ まで急激に増加し，20,000 K で僅か に減少するが，15,000 K 30,000 K まで対数的にほぼ一定 の $10^{9} \mathrm{~W} /\left(\mathrm{m}^{3} \cdot \mathrm{sr}\right)$ 程度となる。この内訳として, 微小な值 ではあるが 4,000 K までは ArI の連続スペクトル $u_{\text {cont }}^{\mathrm{ArI}}$ が,

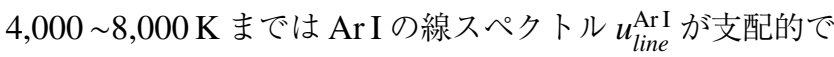
あり，その後 $\mathrm{ArII}$ の連続スペクトル $u_{\text {cont }}^{\mathrm{Ar} I I}$ が増加し続けて支 配的になり，16,000 K でピーク值 $10^{9} \mathrm{~W} /\left(\mathrm{m}^{3} \cdot \mathrm{sr}\right)$ を採り, 以降温度上昇と共に緩やかに減少する。その減少傾向の影 響を受けて， $u_{\text {total }}$ が 20,000 K で若干減少するが, 22,000 K で ArII の線スペクトル $u_{\text {line }}^{\mathrm{ArII}}$ が支配的となり， $u_{\text {total }}$ は，ほほ $10^{9} \mathrm{~W} /\left(\mathrm{m}^{3} \cdot \mathrm{sr}\right)$ 程度に保たれる。このことから $8,000 \mathrm{~K}$ 以 上の高温領域では粒子種として ArII が全放射パワー $u_{\text {total }}$ に大きな影響を与える。また， $8,000 \mathrm{~K}$ 以下の低温領域に 関しては，絶対值は低いものの，ArIが重要な役割を果た す。Ar III の線スペクトル $u_{\text {line }}^{\mathrm{Ar} \text { III, 連続スペクトル } u_{\text {line }}^{\mathrm{Ar} \text { III }} \text { は粒 }}$ 子密度が低いことから，30,000 K においても， $u_{\text {line }}^{\mathrm{Ar} I I}$ の方が 大きいものの， $u_{\text {total }}$ に与える影響は各々 20, 10\%程度，合 計で $30 \%$ と無視できない值に増加した。ArIV は Total に与 える影響は， $30,000 \mathrm{~K}$ でも数\%と小さいと言える。図中の ロは $u_{\text {total }}$ に関する池田氏の計算結果 ${ }^{(12)}$ であり，良い一致 を得た。

$\langle\mathbf{3 \cdot 3}\rangle$ 温度別連続スペクトル $\boldsymbol{u}_{\text {cont }}$ の成分

Biberman

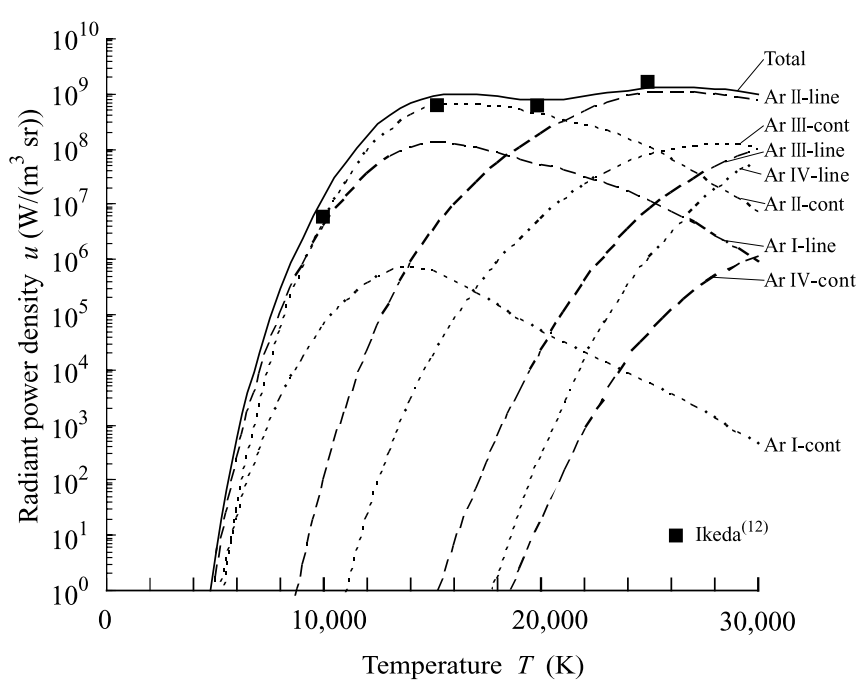

図 2 高温アルゴンガスの全放射パワー密度

(Biberman factor 変化)

Fig. 2. Radiant power density of Ar in high temperature at $0.1 \mathrm{MPa}$ (Biberman factor variable).

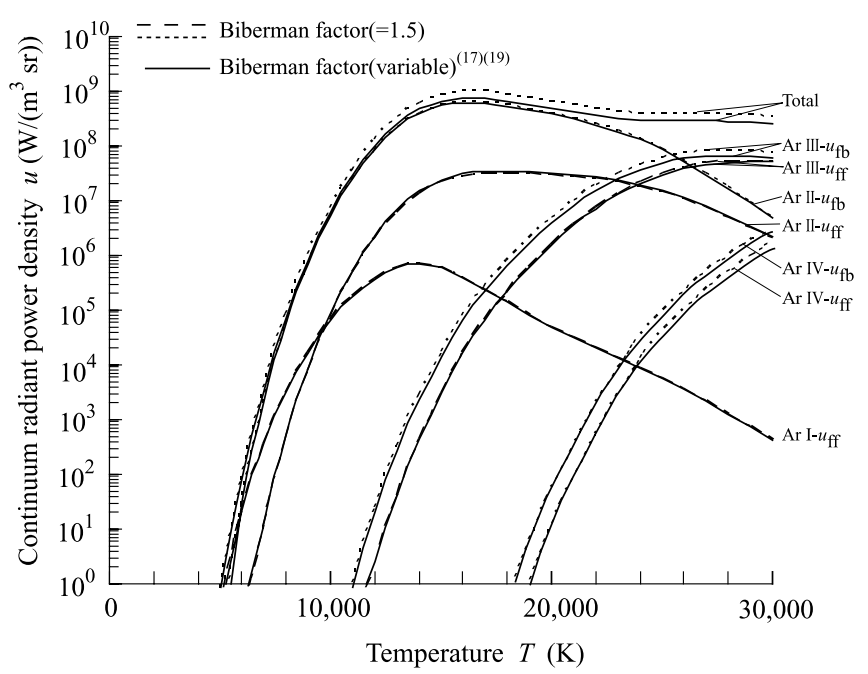

図 3 高温アルゴンガスの連続スペクトル放射 パワー密度

Fig. 3. Continuum radiant power density of $\mathrm{Ar}$ in high temperature argon.

factor を一定 (=1.5) にした時, 及び, 波長で変化させた後 の連続スペクトルの放射パワー密度を比較した結果を図 3 に示す。連続スペクトルの成分を検討するため, 制動放射 と再結合放射をそれぞれ ArI，ArII，ArIIIに分けて示した。 先の図 2 で述べた 4,000 K 以下において支配的な $u_{\text {cont }}^{\mathrm{ArI}}$ は, ArI の制動放射 $u_{f f}^{\mathrm{ArI}}$ であり，8,000 K 20,000 K で支配的 な $u_{\text {cont }}^{\mathrm{Ar} \text { はI }}$ は, ArII の再結合放射 $u_{f b}^{\mathrm{ArII}}$ である。全ての連続ス ペクトルを足し合わせた $u_{\text {cont }}^{\text {total }}$ は, $20,000 \mathrm{~K}$ 以下ではほぼ $u_{f b}^{\mathrm{ArII}}$ に等しく, 20,000 K 以上では $u_{f b}^{\mathrm{ArII}}$ は減少し, ArIIIの 再結合放射 $u_{f b}^{\mathrm{Ar} I I I}$ が支配的となり, $u_{\text {cont }}^{\text {total }}$ の約 6 割程度を占 める。つまり，連続スペクトルの成分としては，8,000 K 以 上の高温領域では，同じ粒子で比較した場合に制動放射は， どの粒子においても再結合放射の值を超えることはなく， 


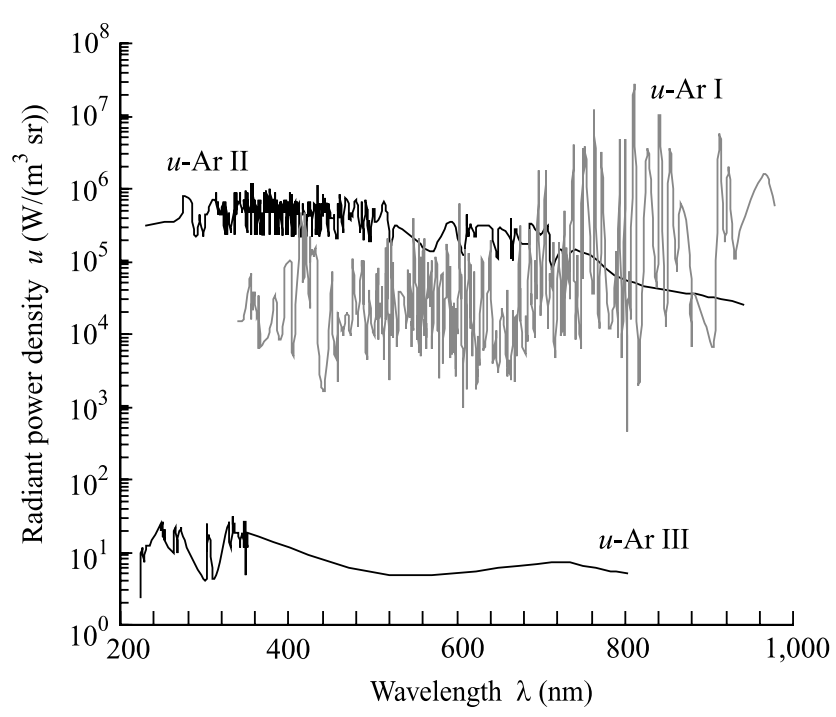

図 4 波長別放射パワー密度 (Biberman factor 変化)

Fig. 4. Radiant power density emitted from Ar in wavelength at $15,000 \mathrm{~K}$ (Biberman factor variable).

連続スペクトルにおいては再結合放射 $u_{f b}$ が重要と判断で きる。ただし，8,000 K 以下では值自体は小さいが $u_{f f}^{\mathrm{ArI}}$ の 影響が大きい。本論文では，特に放射パワー密度が最大值 となる 15,000K に着目しているため，ArIV の影響はほと んどない。

また，Biberman factorを1.5に一定とした場合と比較 すると，変化させることで放射パワー密度の Total は特に $15,000 \mathrm{~K}$ 以上で減少している。この理由として, Biberman factor には電子密度と温度が影響するためと考えられる。こ れは理論式 (4), (6)より, Biberman factor は再結合放射と 制動放射（電子 - イオン）に影響し，線スペクトルと制動放 射（電子 - 原子）には影響しないためである。

〈3.4〉 波長別全放射パワー密度 $\boldsymbol{u}_{\text {total }}$ の粒子別成分 全放射パワー密度 $u_{\text {total }}$ がピークに達する温度として, $15,000 \mathrm{~K}$ における波長別（200～1,000 nm)の全放射パワー 密度を粒子別に求め文献 ${ }^{(17)(19)}$ の, Biberman factor 変化後 の特性曲線を図 4 に示す。まず，図 2 において 15,000 K で は ArI は線スペクトル $u_{\text {line }}^{\mathrm{ArI}}, \operatorname{ArII}$ は再結合放射による連続 スペクトル $u_{f b}^{\mathrm{ArII}}, \mathrm{Ar}$ III は再結合放射による連続スペクトル $u_{f b}^{\mathrm{Ar} I I I}$ が支配的である。図 4 における各粒子別の特性曲線に はこの支配性の影響が現れている。これらの值を波長で積 分した合計值が, 図 2, 図 3 に温度別に示されているが, $15,000 \mathrm{~K}$ においては, $u_{\text {line }}^{\mathrm{ArI}}: 15.1 \%, u_{f b}^{\mathrm{ArII}}: 84.9 \%, u_{f b}^{\mathrm{Ar} I I I}$ : $0.0 \%$ であ。おおよそこの割合がどの波長領域においても 保たれている。700 nm 以上の長波長領域で, 個々には $u_{\text {line }}^{\mathrm{ArI}}$ が $u_{f b}^{\mathrm{ArII}}$ を上回っている波長があるが，そのスペクトル数は 少ない。 $u_{f b}^{\mathrm{ArIII}}$ は, どの波長領域においても $10^{2} \mathrm{~W} /\left(\mathrm{m}^{3} \cdot \mathrm{sr}\right)$ を超えることはなく，他の粒子より $1 / 10^{3} \sim 1 / 10^{4}$ 倍と低 い值となる。

〈3.5〉 波長別連続スペクトル $\boldsymbol{u}_{\text {cont }}$ の成分 さらに連 続スペクトルの構成を見るため, Biberman factor を変化さ

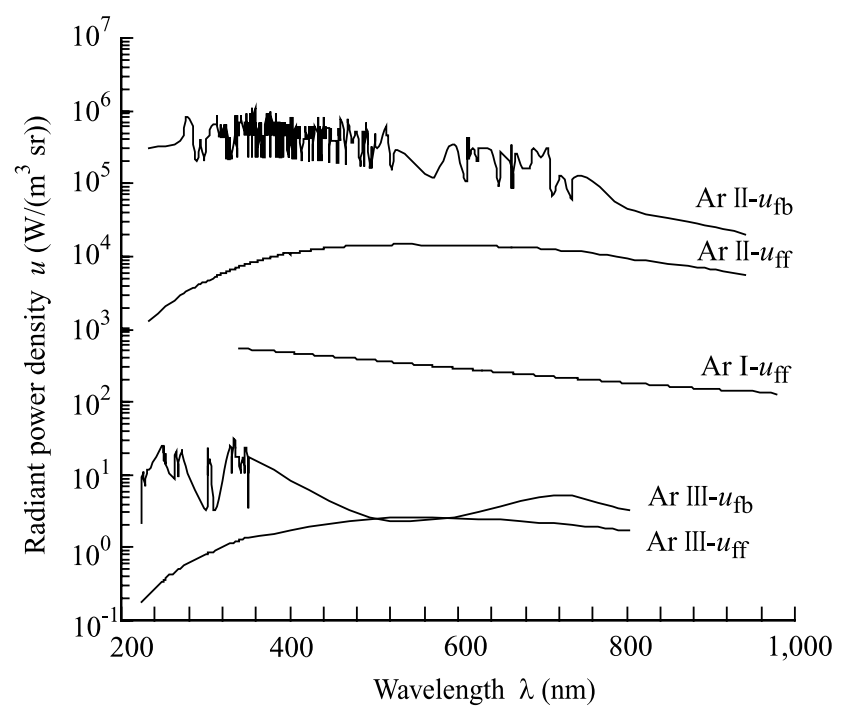

四 5 波長別連続スペクトル放射パワー密度

(Biberman factor 変化)

Fig. 5. Radiant power density of continuum spectra emitted from Ar in wavelength at 15,000 K (Biberman factor variable).

せた $15,000 \mathrm{~K}$ における波長別（200１,000 nm）の連続ス ペクトルの放射パワー密度を図 5 に成分別に示す。制動放 射 $u_{f f}^{\mathrm{ArI}}$ は值が波長に関して連続的で, 波長に強く依存せず ほぼ一定值をとった。 $u_{f b}^{\mathrm{ArII}}$ は, 図 3 で支配的であることを 示したが，本図でもどの波長領域においても支配的となっ た。ここで, 同放射パワー密度の短波長領域における值は 特定の振幅内に収まっている。また，同図において放射ス ペクトルに温度に依存するピークは現れない。これは，温 度が変化すると, 波長領域全体に亘って放射パワー密度が 変化し, 特定の波長のみが変化することは無いことによる。 また, 図 5 で制動放射 $u_{f f}^{\mathrm{ArII}}, u_{f f}^{\mathrm{Ar} I I I}$ は Biberman factor を変化 させることで, $200 \sim 400 \mathrm{~nm}$ で放射パワー密度が急激に上 昇し, $400 \mathrm{~nm}$ 以上は徐々に減少していく山なりの特性曲線 となる。紫外光周辺では制動放射の変化が激しいが, 再結 合放射の方が支配的であるため, 図 4 における紫外光周辺 の変化はあまりない。これらのことから，連続スペクトル の主成分としては再結合放射であり, 制動放射は Biberman factorの影響を受けやすい。

\section{4. 全放射パワー密度の放射領域別成分比}

Biberman factor を変化させた高温アルゴンガスからの放 射パワー密度を紫外・可視・赤外光の 3 波長領域に分類し, その大きさや構成について調べるために，15,000 Kにおけ る全放射パワー密度を $100 \%$ とした時の紫外・可視・赤外光 の波長成分の割合を図 6 に，同様に各原子の線スペクトル， 再結合放射, 制動放射などの各種放射パワー密度を $100 \%$ と した時の波長成分の割合を図 7 に,さらに紫外·可視・赤 外光の放射成分構成を図 8 にそれぞれ示す。

図 6 において，Biberman factorを一定としたときは， 


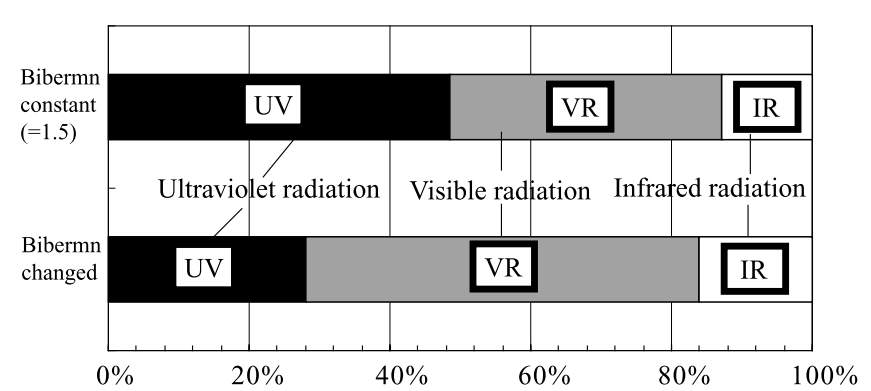

図 6 全放射パワーの紫外・可視・赤外光比

$(15,000 \mathrm{~K})$

Fig. 6. Ratio of ultraviolet, visible and infrared radiation from Ar at 15,000 K and at 0.1 MPa.

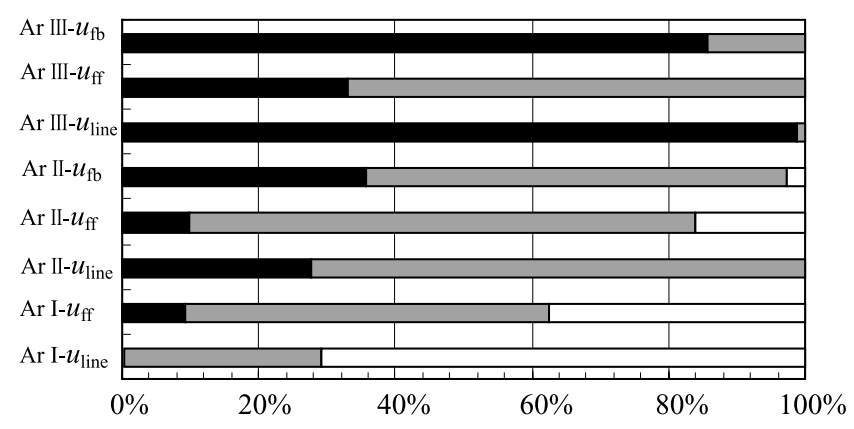

図 7 波長別全放射パワー密度のスペクトル成分 (Biberman factor 変化)

Fig. 7. Spectrum component of radiant power density from $\mathrm{Ar}$ at $15,000 \mathrm{~K}$ and $0.1 \mathrm{MPa}$ (Biberman factor variable).

$15,000 \mathrm{~K}$ における全放射パワーの波長別成分は紫外光： $48.6 \%$, 可視光：38.6\%, 赤外光： $12.8 \%$ という結果が得ら れた。それに対し，Biberman factor を変化させると，紫外 光: $28.1 \%$, 可視光 : $55.9 \%$, 赤外光 : $16.0 \%$ という結果に なり，支配的な波長領域が紫外光から可視光へと大きく変 化した。これは図 7 の $u_{f b}^{\mathrm{ArII}}$ の波長成分割合によく似た傾向 を示す。全放射パワーの赤外光の割合が $u_{f b}^{\mathrm{ArII}}$ の赤外光の割 合より多いが，これには図 2 より同温度において $u_{f b}^{\mathrm{ArII}}$ に次 いで $u_{\text {line }}^{\mathrm{ArI}}$ が支配的であることから， $u_{\text {line }}^{\mathrm{ArI}}$ の大半を占める赤 外光が影響している。

図 7 の割合は, 励起準位がどの波長領域に存在するかに よって決まるため, 温度が変化しても絶対值は変化するが, 波長成分の割合は変化しない。例えば， $u_{\text {line }}^{\text {ArIII }}$ は紫外光が 98.8\%であるので， $u_{\text {line }}^{\mathrm{Ar} I I I}$ が支配的になるアークからは，強 力な紫外光が得られることが予想される。図 8 は, $15,000 \mathrm{~K}$ の $\mathrm{Ar}$ アークから放射される赤外光は $u_{\text {line }}^{\mathrm{ArI}}$, 可視光・紫外光 は $u_{f b}^{\mathrm{ArII}}$ が支配的である。 $u_{f f}^{\mathrm{Ar} I I}$ が数\%の影響を持ち，その他 の放射成分は，1\%にも満たない。以上のことから，高温ア ルゴンガスは全体としては可視光を良く放射するが，各ス ペクトルで注目したときに, 線スペクトル, 制動放射, 再 結合放射で放射パワー密度の成分が異なるため，用途に応 じた使い分けが期待できる。

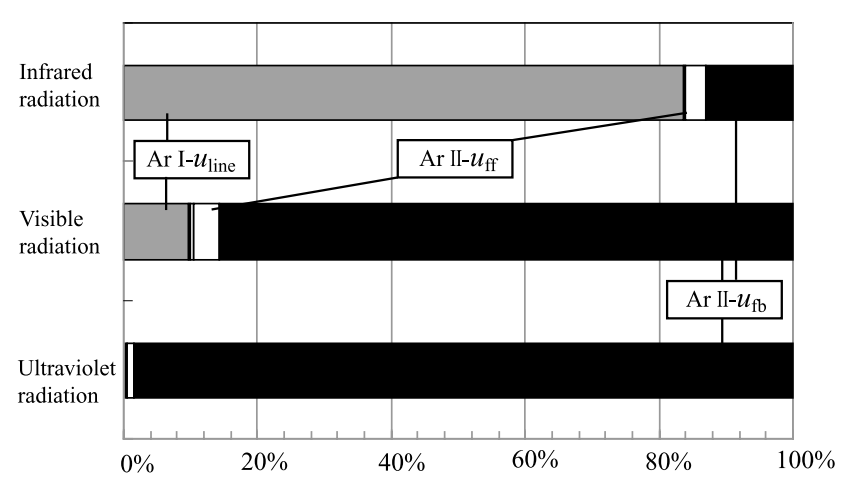

図 8 波長領域別全放射パワー密度

(Biberman factor 変化)

Fig. 8. Radiant power density from Ar as function of wavelength at $15,000 \mathrm{~K}$ and $0.1 \mathrm{MPa}$ (Biberman factor variable).

\section{5. まとめ}

高温 $\mathrm{Ar}$ ガスの放射パワー密度特性を求めるために $0.1 \mathrm{MPa}$ の圧力で粒子組成を計算し, Biberman factor を 波長により変化させ, 線スペクトル・連続スペクトルを粒子 種：Ar I Ar IV, 温度領域：1,000 K 30,000 K, 波長領域： $200 \mathrm{~nm} \sim 1000 \mathrm{~nm}$, と考慮して算出した。特に, Biberman factor 変化時の制動放射と再結合放射から成る連続スペク トルの各成分を波長・温度別に算出し, 波長成分, 放射成 分にわけて検討した。以下に主な結果を示す。

（1） 5,000 K 以下では中性原子 ArI の制動放射による 連続スペクトル, 5,000 9,000 K では ArI の線スペクトル, 9,000 K 22,000 K では一価イオン ArII の再結合放射によ る連続スペクトル，22,000 K 以上では, ArII の線スペクト ルが支配的になる。

（2）連続スペクトルの主成分は再結合放射であり， Biberman factor を波長で変化させた場合, 制動放射は影 響を受けやすい。

(3) 放射パワー密度を紫外・可視・赤外光に分けて計 算した結果，15,000 K において，Biberman factor を一定值 （1.5）から波長に関して変化させると支配的な波長領域が 紫外光 $(49 \%)$ から可視光 $(56 \%)$ と変化する。精度の高 い計算をするためには, Biberman factor を変化させる必要 がある。

(4) Biberman factor 変化時の各種放射別の波長成分 は, ArII の再結合放射と ArI の線スペクトルで大半を占め る結果となった。

（5）以上のことから，高温アルゴンガスは全体として は可視光を良く放射するが，各スペクトルで注目したとき に, 線スペクトル, 制動放射, 再結合放射で放射パワー密度 の成分が異なるため, 用途に応じた使い分けが期待できる。

謝 辞

本研究の実施にあたり, ミネソタ大学 J. Heberlein 教授, 金沢大学田中康規助教授, 名古屋大学横水康伸助教授, 電 
力中央研究所池田弘一主任研究員, 中央大学修論生井上順 恵氏，武蔵工業大学卒論生宮島拓郎氏に解析面でのご協力 を頂き深く感謝致します。なお, 本研究の一部は中央大学 理工学研究所熱プラズマ研究センター（旧文部省私立大学 ハイテク・リサーチ・センター）における“超高温プラズ マ式環境破壊物質無害化・有効活用技術の研究” の一環と して行われた。また，日本学術振興会の科学研究費補助金 (特別研究員奨励費) および特別研究員研究奨励金の補助を 受けた。

(平成 17 年 3 月 1 日受付，平成 17 年 8 月 18 日再受付)

\section{文献}

(1) T. Inaba, S. Kusunoki, T. Iwao, and M. Endo: "Analytical Simulation of Current and Power Parameters on Radiation Energy from High Current WallStabilized Arcs", T. IEE Japan, Vol.118-A, No.1, pp.10-15 (1998-1) (in Japanese)

稲葉次紀・楠 茂幸 ·岩尾 徹 - 遠藤正雄 : 「大電流器壁安定化ア一 クの放射パワーに及ぼす電流と電力パラメータの解析的試算」, 電学 論 A, 118, 1,pp.10-15 (1998-1)

(2) T. Iwao, T. Inaba, and M. Endo: "Radiation Characteristics of Ar Torch Plasma in Middle Current", T. IEE Japan, Vol.118-A, No.9, pp.924-929 (1998-9) (in Japanese)

岩尾 徹・稲葉次紀・遠藤正雄 :「中電流域における $\mathrm{Ar}$ トーチプラ ズマの放射特性」, 電学論 A, 118, 9, pp.924-929 (1998-9)

(3) T. Iwao, H. Miyazaki, T. Hayashi, T. Hirano, and T. Inaba: "Radiation Efficiency of Argon Torch Plasma as Function of the Plasma Length", T. IEE Japan, Vol.120-A, No.12, pp.1063-1069 (2000-12) (in Japanese)

岩尾徹・宮崎宏和・林 龍也・平野貴裕・稲葉次紀：「プラズマ 長変化時のアルゴントーチプラズマの放射効率」, 電学論 A, 120, 12, pp.1063-1069 (2000-12)

(4) T. Iwao, H. Miyazaki, and T. Inaba: "Radiation Characteristics as Function of the Gas Flow-rate emitted from Argon Torch Plasma", T. IEE Japan, Vol.121-A, No.6, pp.528-534 (2001-6) (in Japanese) 岩尾 徹・宮崎宏和・稲葉次紀：「アルゴントーチプラズマにおける ガス流量変化時の放射特性」, 電学論 A, 121, 6, pp.528-534 (2001-6)

( 5 ) T. Iwao, T. Ishida, T. Hayashi, T. Hirano, M. Endo, and T. Inaba: "Examination for Radiation Power Emitted from Ar Torch Plasma As Function of Length", Trans. JIM, Vol.63, No.1, pp.15-20 (1999) (in Japanese) 岩尾 徹·石田貴之·林 龍也·平野貴裕・稲葉次紀·遠藤正雄 :「 $\mathrm{Ar}$ トーチプラズマにおけるプラズマ長変化時の放射パワーの検討」, 金 属学誌, 63, No.1, pp.15-20 (1999)

(6) T. Inaba and T. Iwao: "Treatment of Waste by dc Arc Discharge Plasmas", IEEE, Trans. DEI, Vol.7, No.5, pp.684-692 (2000)

(7) T. Iwao, H. Miyazaki, T. Ishida, Y. Liu, and T. Inaba: "Proposal of Treatment for Hazardous Wastes Using the Highly Concentrated Radiation from Torch Plasma”, Trans. ISIJ International, Vol.40, pp.275-279 (2000)

(8) Y. Liu, Y. Kanazawa, T. Iwao, H. Yoshida, H. Aoki, H. Shindo, and T. Inaba: "Decomposing Biphenyl with a Hollow Cathode Plasma", Trans. MRSJ, Vol.25, pp.381-384 (2000)

(9) J.S. Chang: "Recent Development of Plasma Pollution Control Technology", Proc. PSS-2001, pp.531-534 (2001)

(10) M.1. Boulos, P. Fauchais, and E. Pfender: Thermal Plasmas Fundamentals and Applications, Volume 1, Appendix, Plenum Press (1994)

(11) J. Menart and S. Malik: "Net emission coefficients for argon-iron thermal plasmas", J. Phys, D: Appl. Phys. Vol.35, pp.867-874 (2002)

(12) K. Ikeda, T. Amakawa, and M. Shibuya: "Analysis of Argon Arc Radiance under High Pressure and High Temperature", T. IEE Japan, Vol.120-A, No.4, pp.414-419 (2000-4) (in Japanese) 池田弘一・天川正士・渋谷正豊：「高圧高温アルゴンアークの放射輝 度の解析」, 電学論 A, 120, 4, pp.414-419 (2000-4)

(13) V. Aubrecht, M. Mautlova, F. Urban, and F. Valenta: "Partial Characteristics of Radiation for Thermal Plasmas in $\mathrm{H}_{2} \mathrm{O}$ and Argon", Proc. of the XVth Int. Conf. on Gas Discharges and their Applications, Vol.1, pp.141-144 (2004)

(14) Ch. Deron, Y. Babou, Ph. Riviere, A. Soufiani, and M.-Y. Perrin: "Radiation Transfer in an Argon Atmospheric Plasma: Modelling and Comparision with Experiments", Proc. of the XVth Int. Conf. on Gas Discharges and their Applications, Vol.1, pp.137-140 (2004)

(15) A.T.M. Wilbers, G.M.W. Kroesen, C.J. Timmermans, and D.C. Schram:
"The Continuum emission of an arc plasma", J. Quant. Spectrosc. Radiant. Transfer, Vol.45, No.1, pp.1-10 (1991)

(16) G.J. Bastiaans and R.A. Mangold: "The calculation of electron density and temperature in Ar spectroscopic plasmas from continuum and line spectra", Spectrochim Acta, Vol.40B, No.7, pp.885-892 (1985)

(17) H.R. Griem: Plasma spectroscopy, Chap.6, New York, McGraw-Hill (1964)

(18) T. Iwao, Y. Inoue, Y. Yamaguchi, J. Mizuno, and T. Inaba: "Radiant Power Density under Consideration of Absorption emitted from High Temperature Air mixed with Tungsten Vapor", IEEJ Trans. FM, Vol.123-A, No.7, pp.630-636 (2003-7) (in Japanese)

岩尾 徹・井上順恵・山口慶高・水野仁一・稲葉次紀：「タングステ ン蒸気混入高温空気の吸収を考慮した放射パワー密度」, 電学論 A, 123, 7, pp.630-636 (2003-7)

(19) NIST Atomic Spectra Database Version 3.0 http://physics.nist.gov/PhysRefData/ASD/index.html

20) Y. Tanaka, K.C. Paul, and T. Sakuta: "Thermodynamic and Transport Properties of $\mathrm{N}_{2} / \mathrm{O}_{2}$ Mixtures at Different Admixture Ratios", T. IEE Japan, Vol.120-B, No.1, pp.24-30 (2000-1)

(21) H.P. Schmidt and G. Speckhofer: "Experimental and Theoretical Investigation of High-Pressure Arcs-Part I: The Cylindrical Arc Column (TwoDimensional Modeling)", IEEE Trans. Plasma Sci., Vol.24, No.4, pp.12291238 (1996-8)

（22）堀井憲爾, 他 電気学会 放電ハンドブック出版委員会：放電ハンド ブック 上巻, 第 3 部, 第 5 章, pp.190-201, 電気学会 (1998)

(23) E.J. Robinson and S. Geltman: "Single-and Double-Quantum Photodetachment of Negative Ions and Atoms", Phys. Rev., Vol.153, pp.4-8 (1967)

(24) C.M. Dixon and M.T. Fang: "Moddeling of a wall-stabilized arc subjected to a transverse magnetic field", J. Phys. D: Appl. Phys., Vol.36, pp.2767-2773 (2003)

(25) T. Matsumura, Y. Yokomizu, H. Futamata, and Y. Kito: "Total Radiation Power of 20 kA-Class SF6 Gas-Blast Arcs", T. IEE Japan, Vol.114-A, No.9, pp.585-590 (1994-9) (in Japanese)

松村年郎・横水康伸・二俣浩行・鬼頭幸生：「電流域 $20 \mathrm{kA}$ までの SF6 ガス吹付けアークの全放射パワー」, 電学論 A, 114, 9, pp.585-590 (1994-9)

（26）松村年郎・横水康伸・田中康規：「SF6 ガス熱プラズマの放射」,プラ ズマ応用科学, Vol.5, pp.10-16 (1997)

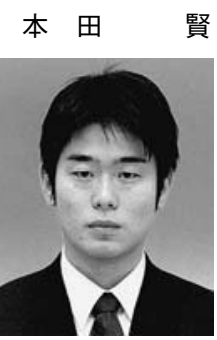

(学生員) 1980 年 10 月 5 日生。 2003 年 3 月中 央大学理工学部電気電子工学科卒業。同年 4 月同 大学大学院理工学研究科電気電子情報通信工学専 攻博士課程前期入学，2005 年 3 月同修了。同年 4 月オリンパス (株) 入社, 現在に至る。在学中, 主として, プラズマアークの放射特性, 高温気体 の粒子組成，輸送特性の研究に従事。

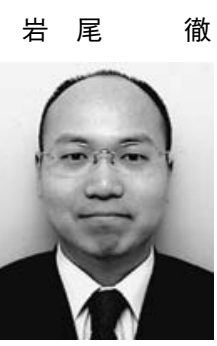

徹 （正員） 1974 年 2 月 15 日生。1997 年中央大学理 工学部卒業。1997，1998 年中大理工研準研究員。 1998 年同大博士課程前期修了。1998 年 CWU 留 学。1999 年同研 RA。2000 年同博士課程後期修 了。2000 年同大理工研ポスドク。2001〜2004 年 学振特別研究員 PD, 中大理工研客員研究員, 阪大 接合研共同研究員, 2001，2002 年テキサステック 大学客員研究員。2002 年放送大学教養学部卒業。 2002，2003 年ミネソタ大学 PD 特別研究員。2004 年武蔵工業大学講 師, 現在に至る。2000 年工学博士。2002 年教養学士。現在, 電気学 会論文委員会委員, アーク・グロー (専) 委員, 大電流 (専) 幹事, 静 止器 (技) 幹事, 2004 年論文委員会幹事。アーク放電, 雷放電, パル スパワーに関する研究，プラズマによる有害物処理等に従事。2000 年 電気学会論文発表賞, 2003 年 JK シンポ優秀論文発表賞受賞。IEEE, 応用物理学会, プラズマ・核融合学会, 日本鉄鋼協会, 廃棄物学会, 放 電学会, プラズマ応用科学会の各会員。E-mail : toruiwao@iwa-net.com 
湯 本 雅 恵 (正員) 1950 年 1 月 17 日生まれ。1978 年 3 月 武蔵工業大学大学院後期博士課程修了。同年 4 月 同大学工学部助手, 1996 年同教授, 2003 年同大 学電気電子情報工学科主任教授となり, 現在に至 る。工学博士。主として, 沿面光物性と放電現象 に関する研究，低気圧中の放電に関する研究に従 事。IEEE 会員。放電技術委員会委員長。
稲 葉 次 紀 （上級会員） 1941 年 2 月 18 日生。1966 年名古屋

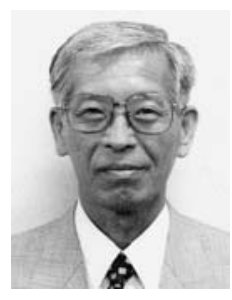
工業大学卒業。1968 年同修士課程修了。1971 年 名古屋大学博士課程満了。1959 年三菱電機, 1965 年アデカ・アーガス化学, 1971 年電力中央研究所 を経て，1994 年より中央大学教授。1971 年工学 博士。アークプラズマ現象，大電流・限流技術， 有害物処理に従事。1978 1979 年西独 Braunschweig 工科大学客員教授。1988 年電気学会評議 委員。2000 2003 放電学会副会長。現在, 電気学会静止器 (技), ヒュー ズ標準化委員会, IEC TC 32·SC32A 国内委員会各委員長, 論文委員, 大電流エネルギー技術 (専) 委員。1976，1988，1995 年電気学会論文 賞, 1994 年同著作賞, 2005 年同グループ著作賞受賞。放電学会, プラ ズマ応用科学会, 低温工学会, 日本金属学会, IEEE 各会員。E-mail： inaba@elect.chuo-u.ac.jp 